\title{
Baseline Sensitivity and Toxic Actions of Prochloraz to Sclerotinia sclerotiorum
}

\author{
Ran Zhang, Qianru Xu, Yuchao Zhang, and Fuxing Zhu, ${ }^{\dagger}$ College of Plant Science and Technology, Huazhong Agricultural University, \\ Wuhan, 430070, China
}

\begin{abstract}
The ergosterol biosynthesis inhibitor prochloraz is a broad-spectrum fungicide and has been registered in China since 2007 for control of the economically important necrotrophic pathogen Sclerotinia sclerotiorum. In this study, relative baseline sensitivity and toxic actions of prochloraz on $S$. sclerotiorum were investigated. The mean $\mathrm{EC}_{50}$ values (effective concentrations causing 50\% mycelial growth inhibition) for isolates collected in $2008(n=73)$ and $2014(n=76)$ were 0.0463 and $0.0434 \mu \mathrm{g} / \mathrm{ml}$, respectively. There was no significant difference $(P=0.348)$ in $\mathrm{EC}_{50}$ values between the two years. Both frequency distributions of $\mathrm{EC}_{50}$ values for 2008 and 2014 were unimodal. The curative efficacy of prochloraz was significantly higher $(P<0.05)$ than that of the reference fungicide carbendazim. Prochloraz in potato dextrose agar (PDA) at concentrations from 0.01 to $0.36 \mu \mathrm{g} / \mathrm{ml}$ had no significant $(P=$ 0.574 ) effects on the weight of sclerotia, but the number of sclerotia per plate increased for treatments with prochloraz at 0.15 and $0.36 \mu \mathrm{g} / \mathrm{ml}$.

Light microscopic observations showed that prochloraz in PDA at $0.03 \mu \mathrm{g} / \mathrm{ml}$ increased the number of hyphal offshoots. Observations with a transmission electron microscope showed that the cell wall of the prochloraz-treated hyphae became thicker and darker than the nontreated control. Prochloraz at 0.01 and $0.04 \mu \mathrm{g} / \mathrm{ml}$ significantly $(P<0.001)$ reduced rather than increased cell membrane permeability. Prochloraz significantly $(P=0.041)$ increased the mannan content in the cell wall of $S$. sclerotiorum. The observed mycelial growth inhibitions for the mixtures of prochloraz at $0.03 \mu \mathrm{g} / \mathrm{ml}$ and Congo red at a dose range from 0.05 to $0.4 \%(\mathrm{w} / \mathrm{v})$ were lower than the expected inhibitions, indicating prochloraz might reduce the content of chitin in S. sclerotiorum. These results demonstrate that prochloraz has significant effects on the morphology and components of the cell wall of S. sclerotiorum and thus will advance our understanding of the toxic actions of prochloraz on phytopathogenic fungi.
\end{abstract}

Sclerotinia sclerotiorum (Lib.) de Bary is a necrotrophic fungal plant pathogen belonging to the family Sclerotiniaceae in the order Helotiales. This fungus can infect more than 400 plant species in 75 families, including many economically important crops and vegetables (Boland and Hall 1994; Bolton et al. 2006). Diseases caused by $S$. sclerotiorum usually lead to serious losses in yield and quality of many crops around the world, especially in relatively cool and moist regions (Purdy 1979). Under adverse conditions, S. sclerotiorum forms pigmented sclerotia capable of overwintering in the soil for many years. Under appropriate conditions in the spring, sclerotia can germinate myceliogenically or carpogenically, thus infecting host plants directly or releasing a tremendous amount of ascospores (Bolton et al. 2006; Zhu et al. 2013). As breeding efforts for highly resistant cultivars have been unsuccessful, diseases caused by S. sclerotiorum have traditionally been difficult to control, and fungicides still remain the principal method for management of this pathogen.

Since the early 1980s, the benzimidazole fungicide carbendazim has been widely used in China to control S. sclerotiorum, and extensive and repetitive applications have led to serious resistance issues. High levels of carbendazim resistance were first reported in 1997 and in the following years became prevalent in East China (Pan 1998; Shi et al. 2000; Zhang et al. 2003). With the development of a high level of resistance to carbendazim, the dicarboximide fungicide dimethachlone was recommended around the year 2000 to control S. sclerotiorum, mainly in East China. Reduced sensitivity to dimethachlone was first reported in 2009 in isolates collected from Jiangsu Province of East China (Ma et al. 2009). A few years later, different levels of dimethachlone resistance developed in northwestern, northeastern, and central China (Zhou et al. 2014a, b).

The demethylation inhibitors (DMIs) comprise a large number of commercially successful fungicides and were first used in agriculture

\section{${ }^{\dagger}$ Corresponding author: F. X. Zhu; E-mail: zhufuxing@mail.hzau.edu.cn}

Funding: This study was supported by the National Natural Science Foundation of China (31371964)

Accepted for publication 23 April 2018.

@ 2018 The American Phytopathological Society in the 1970s. Due to high efficacy and broad-spectrum activity, DMIs are extensively used to control a wide range of fungal plant pathogens (Becher and Wirsel 2012). The mode of action of DMIs is to block the biosynthesis of ergosterol in the fungal cell membrane by inhibiting the demethylation of lanosterol. Ergosterol is one of the most important components of the fungal cell membrane and plays an important role in many cellular processes such as cell membrane fluidity, permeability, and pheromone signaling (Lees et al. 1995; Lepesheva and Waterman 2007; Sombardier et al. 2010; Yun et al. 2014). Four DMI fungicides, i.e., triadimefon, tebuconazole, propiconazole, and prochloraz, have been registered since 2007 to control Sclerotinia stem rot of oilseed rape in China (http://www.chinapesticide. org.cn/hysj/index.jhtml). Prochloraz was launched in 1977 and has been registered for use on more than 30 different crops in 50 countries worldwide (Dyer et al. 2000). Prochloraz is a highly efficient systemic fungicide with broad-spectrum activity (Vinggaard et al. 2006). The toxicity and control efficacy of prochloraz against S. sclerotiorum have been reported in China (Pan et al. 2011; Ren et al. 2010; Sun et al. 2015).

Although prochloraz has been used to control S. sclerotiorum for about one decade, to date, there have been no systematic studies on prochloraz sensitivity in field isolates. Therefore, S. sclerotiorum isolates were collected in 2008 and 2014 from Anhui Province of East China to determine sensitivity to prochloraz. The establishment of baseline sensitivity has long since been a mandatory requirement for registration of a new fungicide in the European Union. Baseline sensitivity is important for monitoring sensitivity shifts in field populations after marketing of a new fungicide (Lu et al. 2015; Russell 2004). However, no baseline sensitivity of $S$. sclerotiorum to prochloraz is available to date. With the development of resistance to carbendazim and dimethachlone, prochloraz is coming to be one of the principal fungicides to control $S$. sclerotiorum. At present, it is impossible to obtain adequate $S$. sclerotiorum isolates without previous exposure to DMI fungicides for the construction of baseline sensitivity. However, if sensitivity to prochloraz has not decreased considerably, relative baseline sensitivity constructed based on sensitivity of isolates that have been exposed to this fungicide would still be valuable for future resistance monitoring programs. In addition, a comprehensive understanding of the toxic actions of prochloraz will be conducive to its judicious applications for controlling phytopathogens. Therefore, the objectives of the present study were to 
(i) establish the relative baseline sensitivity of S. sclerotiorum to prochloraz, (ii) evaluate the preventive and curative efficacy of prochloraz, and (iii) assess toxic actions of prochloraz on S. sclerotiorum, such as effects on sclerotium formation, cell membrane permeability, and hyphal morphology.

\section{Materials and Methods}

Isolates of $S$. sclerotiorum. Mature sclerotia were collected from rapeseed plants in the field with typical symptoms of Sclerotia stem rot. A total of 149 isolates of S. sclerotiorum were collected from rapeseed fields in different regions of Anhui Province of East China. Among these, 73 isolates were collected in 2008 and 76 isolates were collected in 2014 (Table 1). After being air-dried, the collected sclerotia were preserved at $4{ }^{\circ} \mathrm{C}$ in a refrigerator.

Fungicides. Technical grade prochloraz $(97.0 \%$ active ingredient [a.i.], Hubei Kang Bao Tai Fine-Chemical Co. Ltd.) was dissolved in acetone to produce a stock solution at $1,000 \mu \mathrm{g} / \mathrm{ml}$. Technical grade carbendazim (98.1\% a.i., Tian Jin Jin Bei Chemical Co. Ltd.) was dissolved in $0.1 \mathrm{~mol} /$ liter hydrochloric acid $(\mathrm{HCl})$ to produce a stock solution at $1,000 \mu \mathrm{g} / \mathrm{ml}$. These stock solutions were stored at $4{ }^{\circ} \mathrm{C}$ in a refrigerator for no longer than 2 weeks before being serially diluted for subsequent experiments.

Determination of $\mathbf{E C}_{50}$ values and construction of the relative baseline sensitivity of $S$. sclerotiorum to prochloraz. Determination of the effective concentration at which the mycelial growth rate was inhibited by $50 \%\left(\mathrm{EC}_{50}\right)$ was conducted according to $\mathrm{Lu}$ et al. (2015), with slight modifications. A stock solution of prochloraz was serially diluted, and potato dextrose agar (PDA) medium at

Table 1. Geographic origins and numbers of Sclerotinia sclerotiorum isolates collected from Anhui Province

\begin{tabular}{lcc}
\hline & \multicolumn{2}{c}{ Number of isolates } \\
\cline { 2 - 3 } Location (County) & Year 2008 & Year 2014 \\
\hline Anqing & 14 & 40 \\
Chaohu & 29 & 0 \\
Feidong & 0 & 9 \\
Feixi & 0 & 6 \\
Gucheng & 0 & 7 \\
LuAn & 5 & 0 \\
Nanling & 0 & 8 \\
Suzhou & 1 & 0 \\
Wuhu & 1 & 6 \\
Xuancheng & 23 & 0 \\
Total & 73 & 76 \\
\hline
\end{tabular}

A

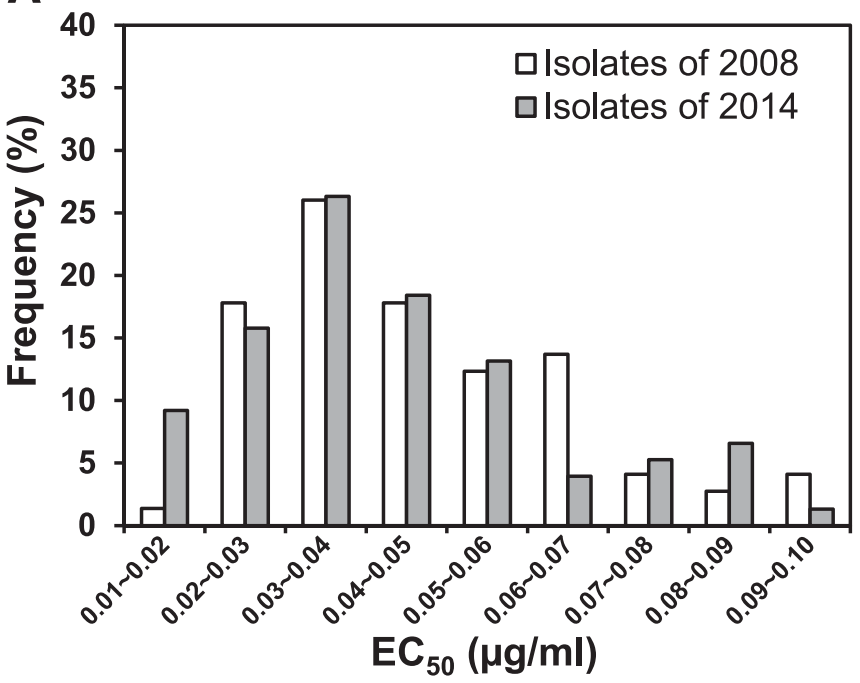

about $50^{\circ} \mathrm{C}$ was amended with prochloraz at final concentrations of $0.01,0.03,0.06,0.1,0.15$, and $0.36 \mu \mathrm{g} / \mathrm{ml}$. PDA supplemented with acetone at a final concentration of $0.2 \%(\mathrm{v} / \mathrm{v})$ was used as the nontreated control. Mycelial plugs cut with a 5-mm diameter cork borer from the fresh margins of 2-day-old colonies were placed onto the center of PDA plates, which were then incubated at $23^{\circ} \mathrm{C}$ for $48 \mathrm{~h}$ in the dark. The diameter of each colony was measured twice at right angles. $\mathrm{EC}_{50}$ values were calculated by the Probit analysis procedure in the software Data Processing System (DPS, ver. 7.05; Hangzhou RuiFeng Information Technology Co. Ltd., Hangzhou, China). The relative baseline sensitivity of prochloraz was constructed based on the frequency distribution of $\mathrm{EC}_{50}$ values.

Preventive and curative efficacy of prochloraz against $\mathbf{S}$. sclerotiorum on potted rapeseed plants. Stock solutions of prochloraz and the reference fungicide carbendazim were diluted with $0.1 \%$ Triton $\mathrm{X}-100$ in water. To determine the preventive efficacy, 4-weekold rapeseed plants growing in pots at $25^{\circ} \mathrm{C}$ were sprayed until run-off with dilutions of prochloraz at 5,10 , and $20 \mu \mathrm{g} / \mathrm{ml}$, and of carbendazim at $20 \mu \mathrm{g} / \mathrm{ml}$ with a handheld sprayer. The treated plants were air-dried for $1 \mathrm{~h}$, inoculated on the adaxial surface with inverted mycelial plugs (one plug per leaf and two leaves per plant) of two arbitrarily selected isolates T27 and LJ36, and then incubated at $25^{\circ} \mathrm{C}$ in a growth chamber with a photoperiod of $16 \mathrm{~h}$ of light and $8 \mathrm{~h}$ of darkness and with relative humidity maintained over $85 \%$ throughout this experiment. Rapeseed plants sprayed with $0.1 \%$ Triton- 100 in water were used as the nontreated control. Lesion diameters were measured in two perpendicular directions after $48 \mathrm{~h}$ of incubation.

For determination of the curative efficacy, rapeseed plants were inoculated with mycelial plugs cut from the fresh margins of 2-day-old colonies and incubated at $25^{\circ} \mathrm{C}$ for $18 \mathrm{~h}$ and then sprayed as described above with prochloraz dilutions at 10,30 , and $90 \mu \mathrm{g} / \mathrm{ml}$, and with carbendazim at $30 \mu \mathrm{g} / \mathrm{ml}$. The treated plants were airdried for $1 \mathrm{~h}$ and incubated at $25^{\circ} \mathrm{C}$ in a growth chamber. Lesion diameters were measured in two perpendicular directions $48 \mathrm{~h}$ after fungicide applications. All experiments in the study were conducted in triplicate and repeated independently at least twice unless stated otherwise.

Effect of prochloraz on sclerotium formation. Four isolates of S. sclerotiorum, i.e., T5, T27, LJ35, and LJ36, were arbitrarily selected and prochloraz $\mathrm{EC}_{50}$ values for the four isolates were 0.053, 0.052, 0.053 , and $0.090 \mu \mathrm{g} / \mathrm{ml}$, respectively. Mycelial plugs of each isolate were transferred onto PDA plates amended with prochloraz at the ultimate concentrations of $0.01,0.03,0.06,0.1,0.15$, and $0.36 \mu \mathrm{g} / \mathrm{ml}$. PDA amended with acetone at $0.2 \%(\mathrm{v} / \mathrm{v})$ were used as the nontreated control. Six replicate PDA plates for each isolate were incubated at $23^{\circ} \mathrm{C}$ in the dark for 30 days. Sclerotia formed on each PDA plate

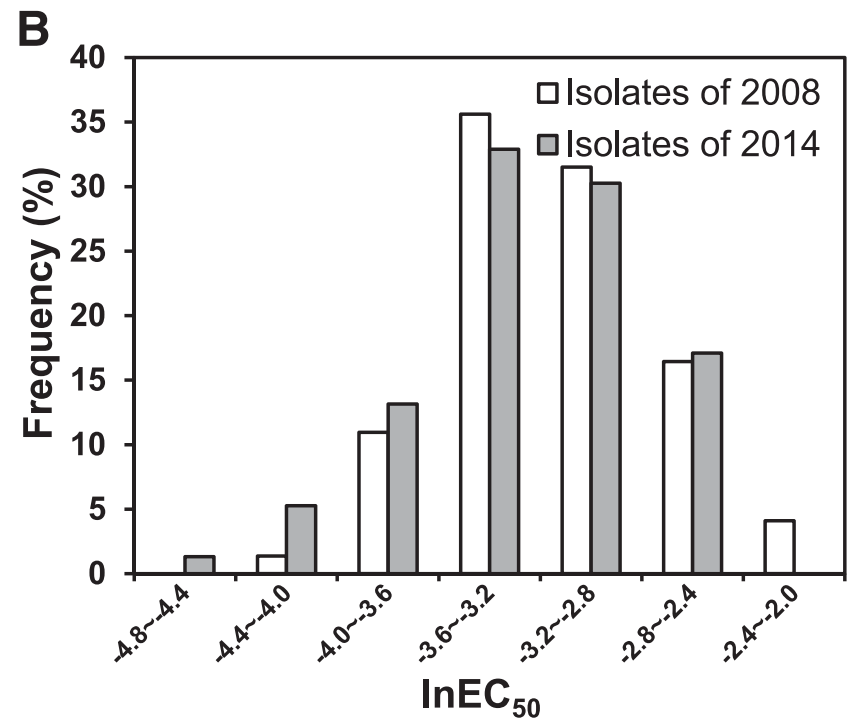

Fig. 1. Frequency distribution of $\mathbf{A}$, the effective concentration at which mycelial growth was inhibited by $50 \%\left(E C_{50}\right)$ values and $\mathbf{B}$, natural logarithms (In) of $E C_{50}$ values of prochloraz to Sclerotinia sclerotiorum. Seventy-three and 76 isolates were collected in 2008 and 2014, respectively, from oilseed rape fields in Anhui Province of China. 
were counted. All sclerotia in each plate were weighed after being dried for an additional 4 weeks at room temperature.

Light microscopy and transmission electron microscopy (TEM) observations of the effect of prochloraz on hyphal morphology. Light microscopic observations of the morphology of hyphae were according to Duan et al. (2013). Mycelia of isolate T27 were grown at $23^{\circ} \mathrm{C}$ for $48 \mathrm{~h}$ on cellophane-overlaid PDA amended with prochloraz at $0.03 \mu \mathrm{g} / \mathrm{ml}$. PDA plugs $(10 \mathrm{~mm} \times 10 \mathrm{~mm})$ were cut with a scalpel from the actively growing margins of mycelial colonies and pieces of cellophane with mycelia on them were put on slides. Hyphal morphology was observed with a light microscope. TEM observations were performed according to Lu et al. (2015) and Yu et al. (2012). Mycelia of isolate $\mathrm{T} 27$ grown at $23^{\circ} \mathrm{C}$ for $48 \mathrm{~h}$ on cellophane-overlaid PDA containing prochloraz at $0.03 \mu \mathrm{g} / \mathrm{ml}$ were harvested by gentle scraping with a scoop. Mycelia grown on PDA amended with acetone free of prochloraz were used as the nontreated control. The samples were fixed at $4{ }^{\circ} \mathrm{C}$ for $6 \mathrm{~h}$ in $4 \%$ (v/v) glutaraldehyde in $100 \mathrm{mM}$ phosphate buffer $(\mathrm{pH}=7.2)$, thoroughly rinsed with phosphate buffer, postfixed with osmium tetroxide at $4^{\circ} \mathrm{C}$ for $2 \mathrm{~h}$, and dehydrated in a graded acetone series from 30 to $100 \%$. The samples were then embedded in
A

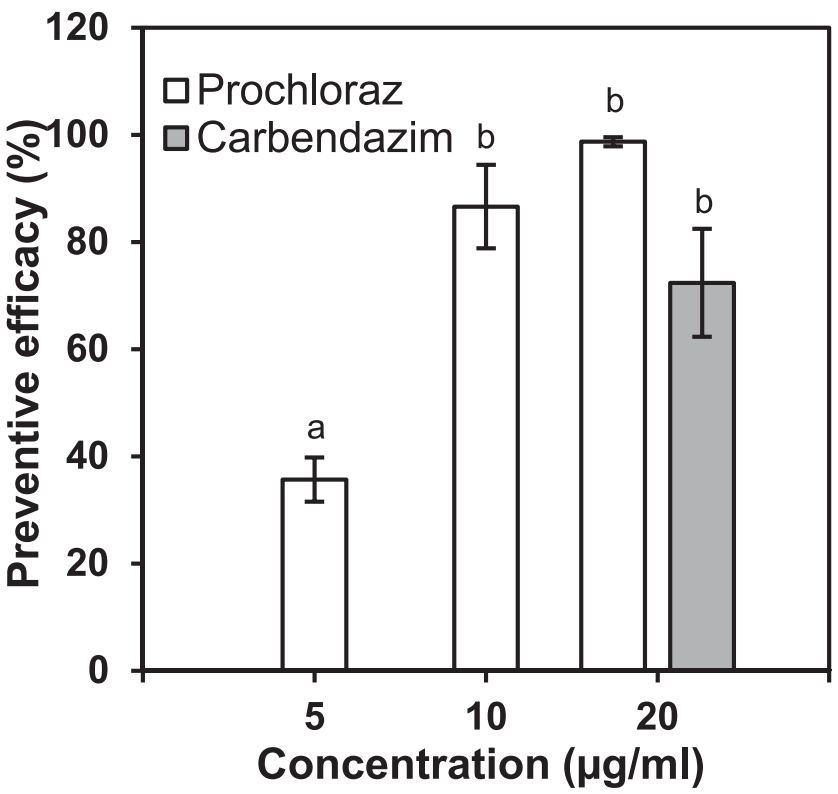

B

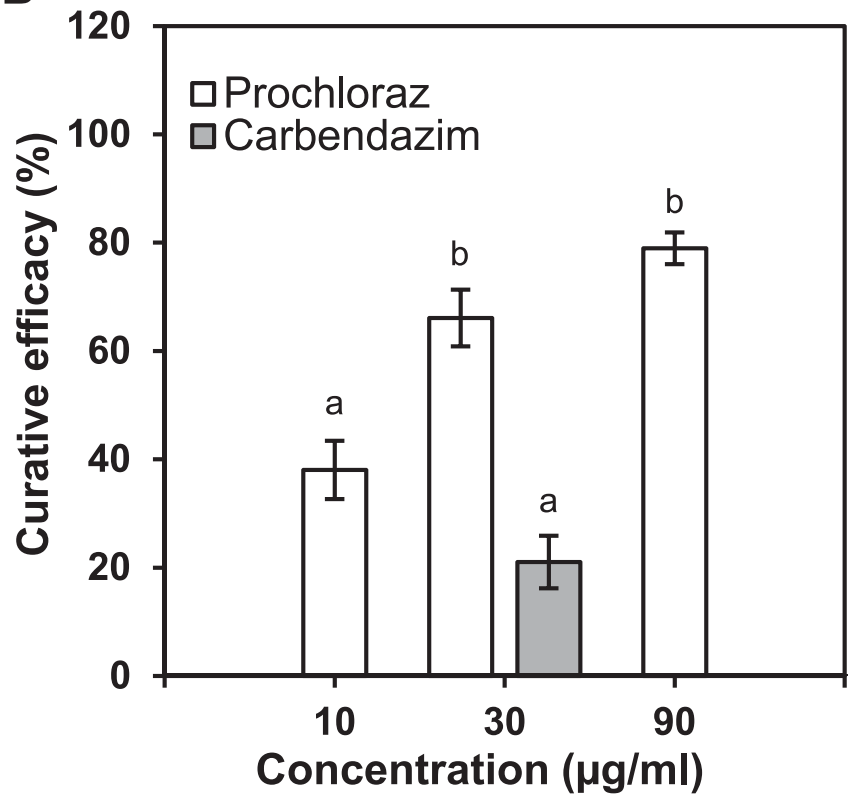

Fig. 2. A, Preventive efficacy and B, curative efficacy of prochloraz and carbendazim against Sclerotinia sclerotiorum. Data are the means of two isolates T27 and LJ36, each with two data points of repeated experiments. Error bar denotes the standard error of the mean. Different lower case letters denote significant differences at $\alpha=0.05$ according to Tukey's Multiple Comparison Test in Graphpad Prism (ver. 5.01).

A

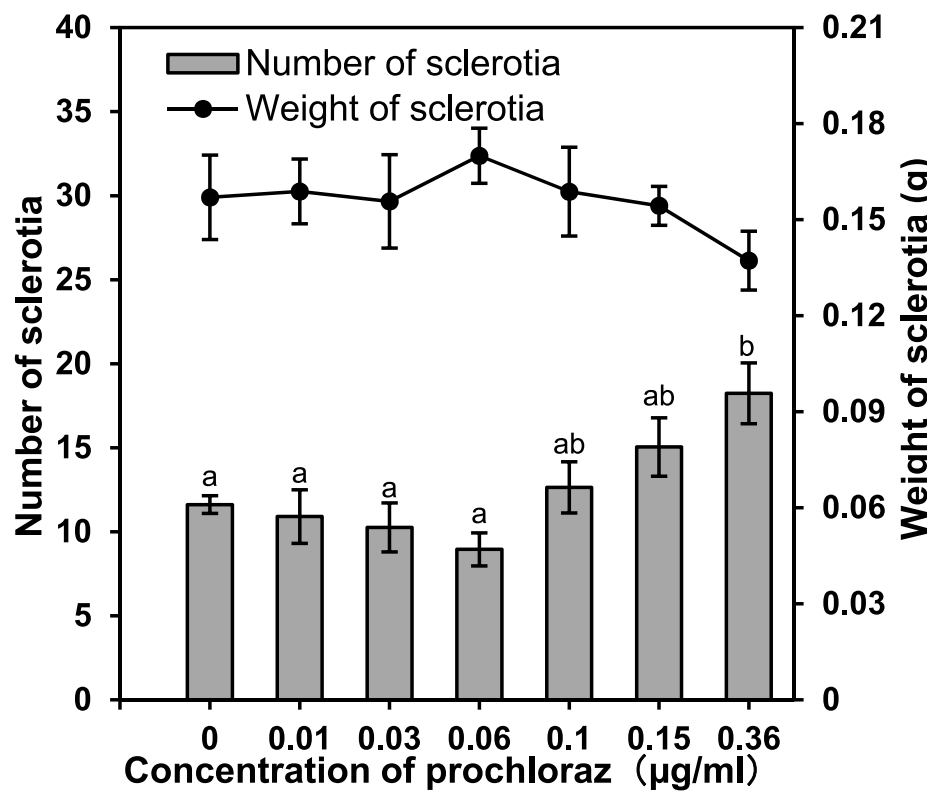

B

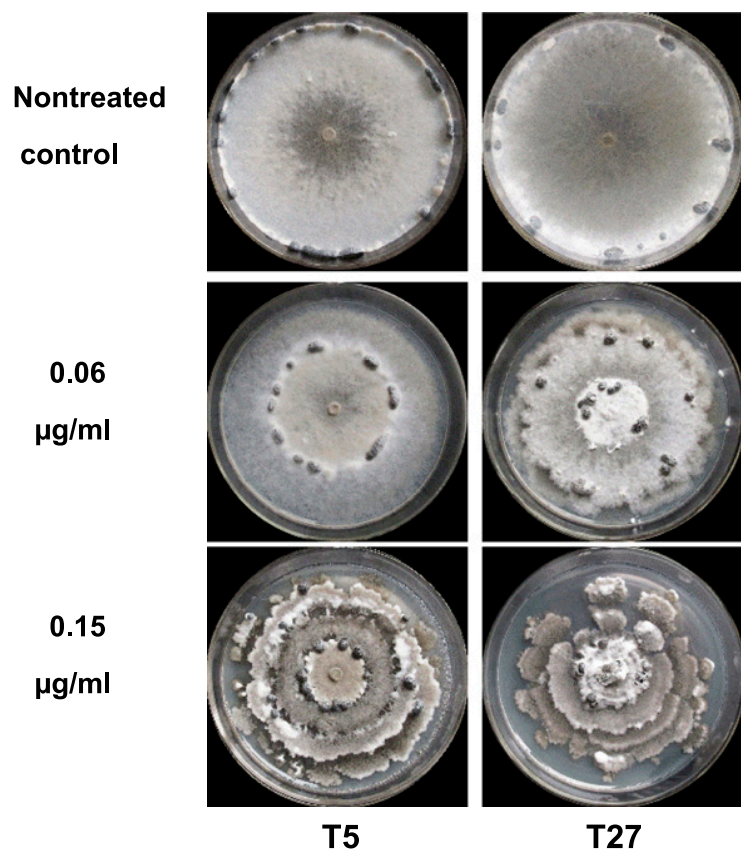

Fig. 3. Effects of prochloraz on A, the number and weight of sclerotia per plate and B, sclerotial development of isolates T5 and T27 of Sclerotinia sclerotiorum. Data are the means of four replicate isolates. Error bar denotes the standard error of the mean. Different lower case letters denote significant differences at $\alpha=0.05$ according to Tukey's Multiple Comparison Test in Graphpad Prism (ver. 5.01). These pictures of sclerotia were taken after 30 days of incubation. 
Epon-821 resin (Hexion Inc., Columbus, $\mathrm{OH}$ ) and polymerized at $60^{\circ} \mathrm{C}$ for $24 \mathrm{~h}$. Ultra-thin sections $(50 \mathrm{~nm})$ were cut from the samples on a Leica Ultracut UCT ultramicrotome with a diamond knife and collected onto 200-mesh copper grids. After being contrasted with uranyl acetate and lead citrate, the grids were examined with an electron microscope H-7650 (HITACHI Inc., Japan) at $80 \mathrm{KV}$.

Effect of prochloraz on the permeability of mycelial cell membrane. Mycelial cell membrane permeability was measured according to Duan et al. (2013) and Lu et al. (2015), with minor modifications. After the two arbitrarily selected isolates, T5 and T27, had been grown at $23^{\circ} \mathrm{C}$ for $48 \mathrm{~h}$ on cellophane-overlaid PDA containing prochloraz at $0.01,0.04 \mu \mathrm{g} / \mathrm{ml}$, or containing acetone at $0.2 \%(\mathrm{v} / \mathrm{v})$ as the nontreated control, mycelia were harvested by gentle scraping with a scoop. Approximately $0.20 \mathrm{~g}$ of mycelia per sample was suspended in $35 \mathrm{ml}$ of double-distilled water in a 50-ml sterilized beaker, and the beaker was shaken for $3 \mathrm{~s}$ by hand. At 5, 10, 20, 40, 60, 80, 100, $120,140,160$, and $180 \mathrm{~min}$ after suspension, the electrical conductivity of the double-distilled water was measured at room temperature with an electrical conductivity meter (DDS-12DW, Shuanxu Electronics Co. Ltd., Shanghai, China). After $180 \mathrm{~min}$ of suspension, the mycelia were boiled for $5 \mathrm{~min}$, and the final conductivity was measured. The relative conductivity was calculated by the following formula: relative conductivity $(\%)=$ conductivity/the final conductivity $\times 100 \%$.

Determination of the effect of prochloraz on mannan content. The mannan content in mycelia was measured according to Chen et al. (2016), with some modifications. A standard aqueous solution of mannose was prepared by dissolving $0.0500 \mathrm{~g}$ of mannose in $100 \mathrm{ml}$ of double-distilled water. To generate a standard curve for assaying mannose, $0,0.025,0.05,0.1,0.2,0.4$, and $0.8 \mathrm{ml}$ of the standard mannose solution at $500 \mu \mathrm{g} / \mathrm{ml}$ were pipetted to glass test tubes with stoppers. For each of the test tubes, double-distilled water was added to a final volume of $1 \mathrm{ml}$, and $1 \mathrm{ml}$ of phenol at $6 \%(\mathrm{v} / \mathrm{v})$ was added and vortexed. Then, $5 \mathrm{ml}$ of concentrated sulfuric acid $\left(\mathrm{H}_{2} \mathrm{SO}_{4}\right)$ was added slowly into each of the test tubes. After being vortexed, the test tubes were incubated in boiling water for $20 \mathrm{~min}$. After cooling down to room temperature, the absorbance of the reaction solution was measured at $490 \mathrm{~nm}$ with a UV-1800 spectrophotometer (SHIMADZU Corporation, Japan). A standard curve was produced by plotting absorbance against mannose concentrations.

Mycelia of isolate T27 grown on cellophane-overlaid PDA containing prochloraz at 0.01 and $0.03 \mu \mathrm{g} / \mathrm{ml}$ were harvested by gentle scraping with a scoop. Mycelia grown on PDA supplemented with acetone at $0.2 \%(\mathrm{v} / \mathrm{v})$ were used as the nontreated control. The collected mycelia were lyophilized and ground in liquid nitrogen to a fine powder with a mortar and pestle, and $0.0500 \mathrm{~g}$ powder of each sample was suspended in $2 \mathrm{ml}$ of $0.6 \%$ sodium hydroxide $(\mathrm{NaOH})$ solution in a test tube. The tubes were incubated at $75^{\circ} \mathrm{C}$ in a water bath for $30 \mathrm{~min}$. After cooling down to room temperature, the sample suspensions were centrifuged at $13,000 \mathrm{rpm}$ for $10 \mathrm{~min}$ and $1 \mathrm{ml}$ of the supernatant was used to determine mannan content with the same set of procedures as used for the establishment of mannose standard curve.

Determination of the effects of prochloraz on chitin content and cell membrane integrity of $S$. sclerotiorum. The effect of prochloraz on chitin content was measured according to Zhang et al. (2010) and Ram and Klis (2006), with some modifications. Mycelial plugs were transferred onto PDA plates containing $0,0.05,0.1,0.2$, $0.4,0.8,1.2$, and $1.6 \%(\mathrm{w} / \mathrm{v})$ of Congo red with or without $0.03 \mu \mathrm{g} / \mathrm{ml}$ prochloraz. For determination of the effect of prochloraz on cell membrane integrity, mycelial plugs were transferred onto PDA plates amended with $0.005,0.01,0.02,0.04$, and $0.08 \%(\mathrm{w} / \mathrm{v})$ of sodium dodecyl sulfate (SDS) with or without $0.03 \mu \mathrm{g} / \mathrm{ml}$ prochloraz. PDA plates supplemented with acetone were used as the nontreated control. The PDA plates were incubated at $23^{\circ} \mathrm{C}$ for $48 \mathrm{~h}$ in the dark. The diameter of each colony was measured twice at right angles. Percent inhibitions of mycelial growth were calculated by the formula: percent inhibition $=($ colony diameter of the nontreated control colony diameter of the treated)/(colony diameter of the nontreated control $) \times 100 \%$. The expected percent inhibitions for the mixture of prochloraz with Congo red or SDS were calculated according to the method of Bliss (Harris and Chambers 1973), with the formula: expected percent inhibition $=$ percent inhibition of Congo red or SDS + percent inhibition of prochloraz - (percent inhibition of Congo red or SDS $\times$ percent inhibition of prochloraz).

Data processing and analysis. For estimation of $\mathrm{EC}_{50}$ values, concentrations of prochloraz were logarithmically transformed and percent inhibitions were converted to probit values. $\mathrm{EC}_{50}$ values were calculated with the Probit procedure in the statistical software Data Processing System (DPS, version 7.05; Hangzhou Ruifeng Information Technology Co. Ltd.). Prochloraz efficacy was calculated by the following formula: preventive (or curative) efficacy $(\%)=($ lesion diameter of the control - lesion diameter of the treated)/lesion diameter of the control $\times 100 \%$. There was no significant difference in efficacy between the two isolates tested, and therefore data for the two isolates were pooled together for statistical analysis. Control efficacy data were arcsine-square-root-transformed and Tukey's multiple comparison test in one way analysis of variance (ANOVA) in GraphPad Prism (version 5.01; GraphPad Software, Inc.) was employed to compare control efficacies among different treatments.

\section{Results}

Relative baseline sensitivity of $S$. sclerotiorum to prochloraz. Both frequency distributions of $\mathrm{EC}_{50}$ values for the isolates collected in 2008 and in 2014 were unimodal (Fig. 1). The mean $\mathrm{EC}_{50}$ value for
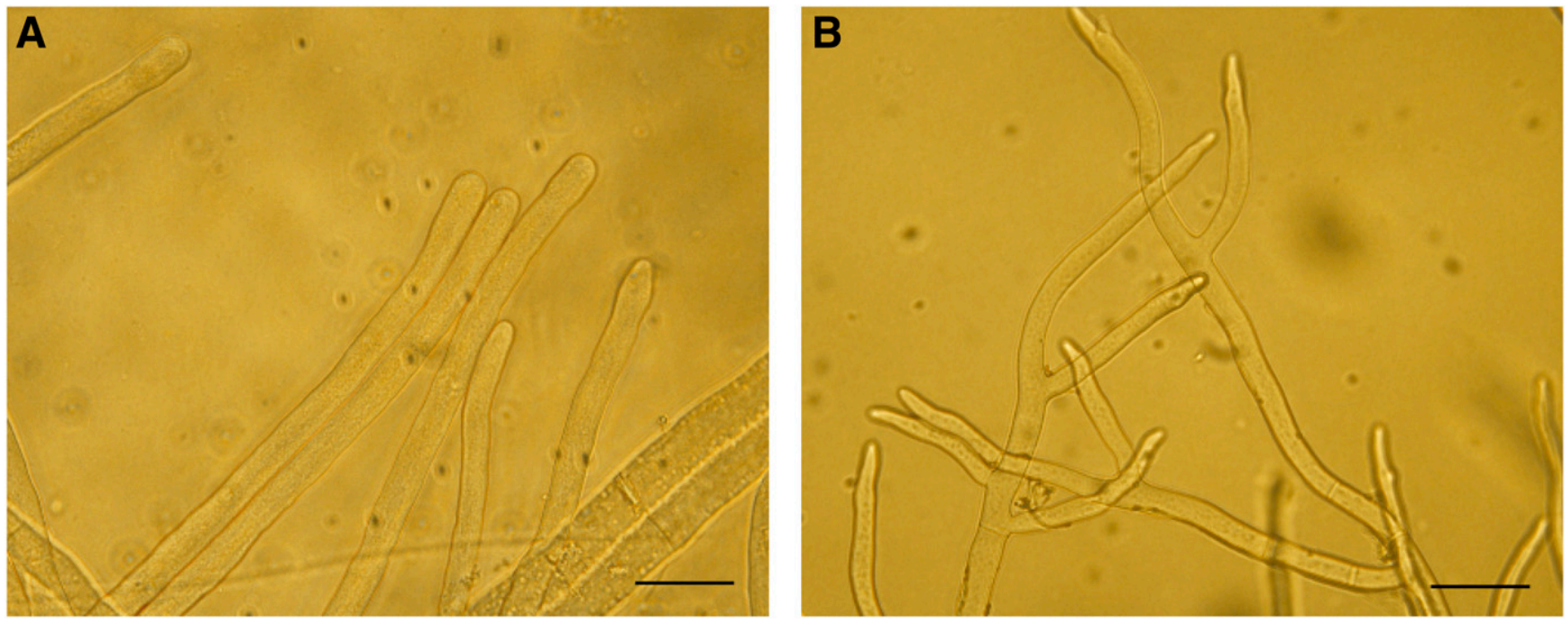

Fig. 4. Effects of prochloraz on hyphal morphology of Sclerotinia sclerotiorum isolate T27. Micrograph A is the nontreated control and $\mathbf{B}$ is the hyphae grown on PDA amended with prochloraz at $0.03 \mu \mathrm{g} / \mathrm{ml}$. Scale bar is $50 \mu \mathrm{m}$. 
the 73 isolates of 2008 was $0.0463 \mu \mathrm{g} / \mathrm{ml} \pm 0.0190$ (standard deviation, SD) and the $\mathrm{EC}_{50}$ range was from 0.016 to $0.0992 \mu \mathrm{g} / \mathrm{ml}$. The mean $\mathrm{EC}_{50}$ value for the 76 isolates of 2014 was $0.0434 \mu \mathrm{g} / \mathrm{ml} \pm$ 0.0193 (SD) and the $\mathrm{EC}_{50}$ range was from 0.0113 to $0.0907 \mu \mathrm{g} / \mathrm{ml}$. Student's $t$ test showed that there was no significant difference in $\mathrm{EC}_{50}$ values $(P=0.348)$ or in natural logarithms of $\mathrm{EC}_{50}$ values
$(P=0.211)$ between 2008 and 2014. The two baselines based on $\mathrm{EC}_{50}$ values and logarithms were similar in shape.

Prochloraz $\mathrm{EC}_{50}$ values fitted a normal (Gaussian) distribution, with $P=0.181$ for the isolates of 2008 and $P=0.526$ for the isolates of 2014 being detected by KS Normality Test in the software GraphPad Prism (ver. 5.01). After logarithmic transformation of the $\mathrm{EC}_{50}$
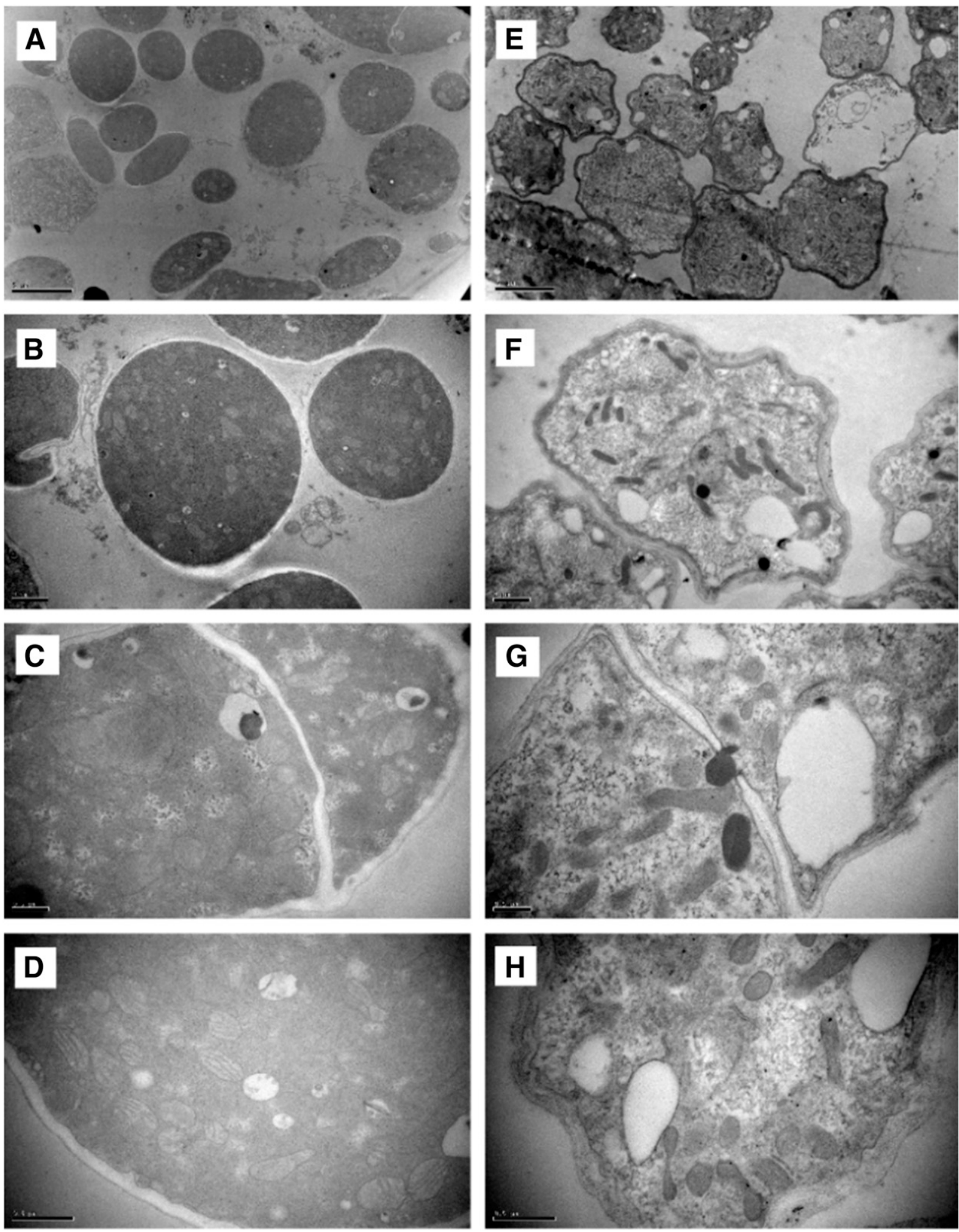

\section{Nontreated control}

Treated with prochloraz

Fig. 5. Transmission electron micrographs of hyphae of Sclerotinia sclerotiorum isolate T27 grown on PDA with or without prochloraz. Micrographs $\mathbf{A}, \mathbf{B}, \mathbf{C}$, and $\mathbf{D}$ are the nontreated controls, while $\mathbf{E}, \mathbf{F}, \mathbf{G}$, and $\mathbf{H}$ are treated with prochloraz at $0.03 \mu \mathrm{g} / \mathrm{ml}$ in PDA medium. Scale bars for micrographs $\mathbf{A}$ and $\mathbf{E}$ are $5 \mu \mathrm{m}$, for $\mathbf{B}$ and $\mathbf{F}$ are $1 \mu \mathrm{m}$, and for $\mathbf{C}, \mathbf{D}, \mathbf{G}$, and $\mathbf{H}$ are $0.5 \mu \mathrm{m}$. 
values, the data fitted a normal distribution better, with $P=0.947$ and $P=0.938$ being detected for the isolates of 2008 and 2014, respectively.

Preventive and curative efficacies of prochloraz against S. sclerotiorum. Prochloraz sprayed at $20 \mu \mathrm{g} / \mathrm{ml}$ provided a preventive efficacy of $98.7 \%$ against $S$. sclerotiorum on potted rapeseed plants (Fig. 2A). Preventive efficacies of prochloraz at 10 and $20 \mu \mathrm{g} / \mathrm{ml}$ were slightly but not statistically significantly $(P>0.05)$ higher than that of the reference fungicide carbendazim at $20 \mu \mathrm{g} / \mathrm{ml}$. Curative efficacies of prochloraz at 30 and $90 \mu \mathrm{g} / \mathrm{ml}$ were 66.1 and $79.0 \%$, respectively, which were significantly $(P=0.001)$ higher than that of carbendazim at $30 \mu \mathrm{g} / \mathrm{ml}$ (Fig. 2B).

Effect of prochloraz on sclerotium formation. Significantly more $(P=0.0382)$ sclerotia were produced on PDA containing prochloraz at $0.36 \mu \mathrm{g} / \mathrm{ml}$ than the nontreated control, whereas prochloraz at concentrations from 0.01 to $0.15 \mu \mathrm{g} / \mathrm{ml}$ had no significant effect on the number of sclerotia (Fig. 3A). Compared with the nontreated control, prochloraz had no significant $(P=$ 0.574 ) effect on the weight of the sclerotia. For the nontreated control and treatments with prochloraz at 0.01 or $0.03 \mu \mathrm{g} / \mathrm{ml}$, sclerotia were formed mainly on the periphery of mycelial colonies (Fig. 3B). For prochloraz at $0.06 \mu \mathrm{g} / \mathrm{ml}$ or higher concentrations, most of the sclerotia were produced along middle circles of mycelial colonies and obviously smaller than those of the nontreated control.

Effect of prochloraz on hyphal morphology of S. sclerotiorum. Light microscopic observations showed that prochloraz increased the number of hyphal offshoots, and the tips of hyphae grown on PDA supplemented with prochloraz at $0.03 \mu \mathrm{g} / \mathrm{ml}$ were more pointed and much thinner than the nontreated control (Fig. 4). TEM observations also indicated that prochloraz had substantial effects on hyphal morphology of S. sclerotiorum (Fig. 5). After growing for $48 \mathrm{~h}$ on PDA amended with prochloraz at $0.03 \mu \mathrm{g} / \mathrm{ml}$, hyphal cells shrank and cell wall became rougher, darker, and thicker than the nontreated control. In addition, the spindle-shaped mitochondria were clearly observed in the nontreated control, while the mitochondria in the prochloraz treated hyphae were apparently deformed.

Effect of prochloraz on mycelial cell membrane permeability. Cell membrane permeability was represented by the relative conductivity of distilled water containing mycelia. Prochloraz at 0.01 and $0.04 \mu \mathrm{g} / \mathrm{ml}$ reduced cell membrane permeability of the two isolates T5 and T27 (Fig. 6). The differences in cell membrane permeability between the nontreated control and the treatments with prochloraz at 0.01 and $0.04 \mu \mathrm{g} / \mathrm{ml}$ were statistically significant $(P \leq 0.001)$ for both isolates. Prochloraz at $0.04 \mu \mathrm{g} / \mathrm{ml}$ reduced cell membrane permeability to a greater extent than at $0.01 \mu \mathrm{g} / \mathrm{ml}$.

Effect of prochloraz on mannan content in mycelia. Compared with the nontreated control, mannan content increased considerably for mycelia grown on PDA amended with prochloraz (Fig. 7). Mannan weight percentages for mycelia grown on PDA without prochloraz, and supplemented with prochloraz at 0.01 and $0.03 \mu \mathrm{g} / \mathrm{ml}$ were $1.60,3.14$, and $3.45 \%$, respectively. There were significant $(P=0.041)$ differences in mannan content between the nontreated control and the treatment with prochloraz at $0.03 \mu \mathrm{g} / \mathrm{ml}$.

The effects of prochloraz on chitin content and cell membrane integrity of $S$. sclerotiorum. The percent inhibition of mycelial growth was $38.1 \%$ for treatment with prochloraz at $0.03 \mu \mathrm{g} / \mathrm{ml}$. Reagent Congo red binds to chitin of fungal cell wall, and reduced

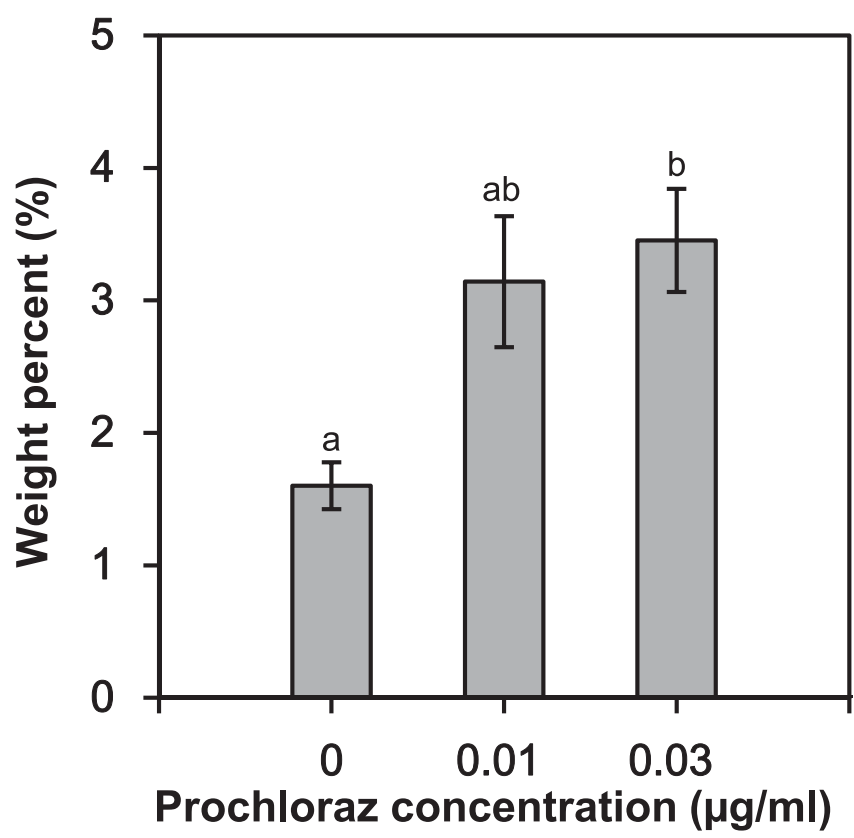

Fig. 7. Effect of prochloraz on mannan content in mycelia of Sclerotinia sclerotiorum isolate T27. Error bar denotes the standard error of the mean of three repeated experiments. Different lower case letters denote significant differences at $\alpha=0.05$ according to Tukey's Multiple Comparison Test in Graphpad Prism (ver. 5.01).
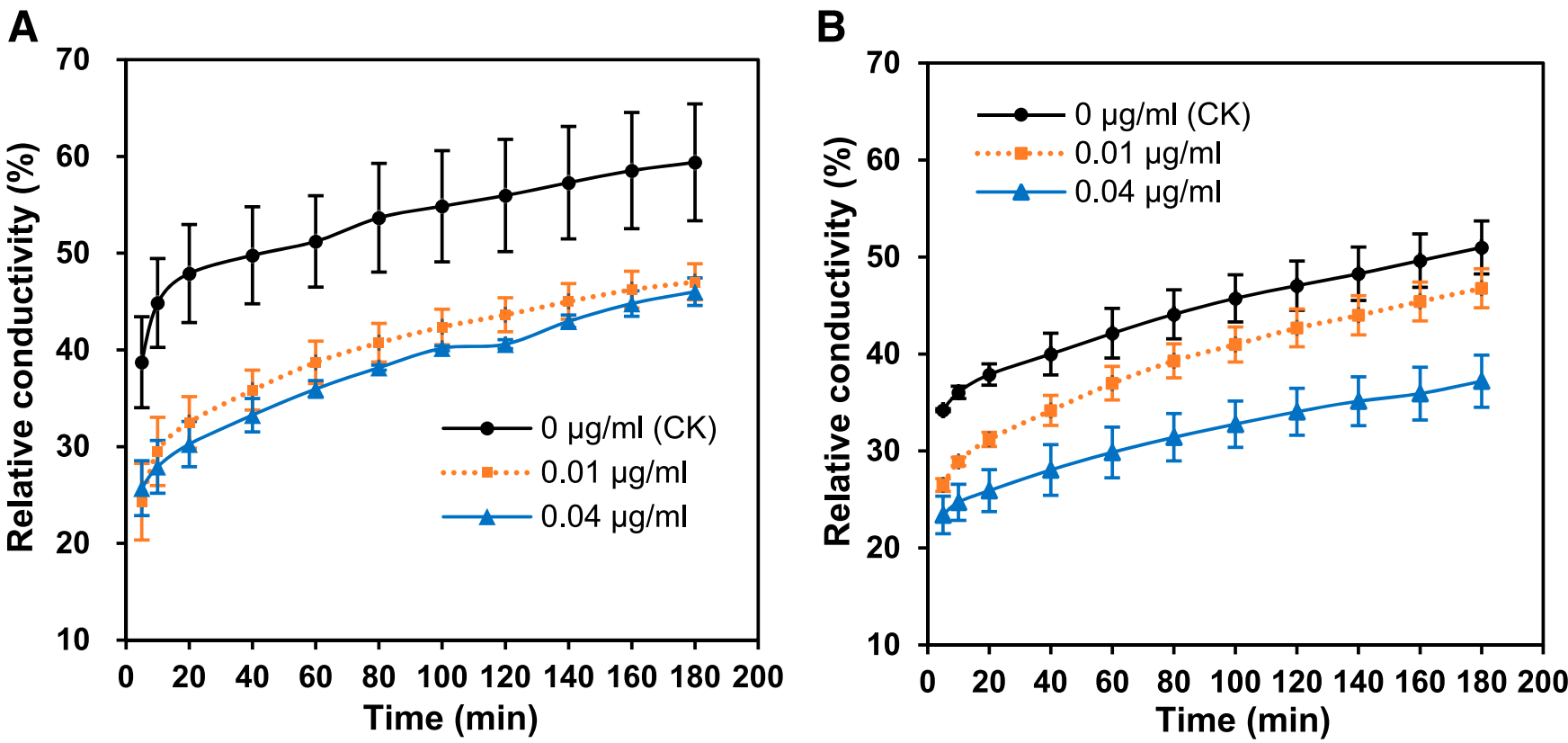

Fig. 6. Relative conductivity of water containing mycelia of Sclerotinia sclerotiorum $\mathbf{A}$, isolate T5 and B, isolate T27 grown on PDA amended with prochloraz ( $0 \mu \mathrm{g} / \mathrm{ml}$ as the nontreated control). Error bar denotes the standard error of the mean of three repeated experiments. 
sensitivity to Congo red may indicate lower chitin content in the cell wall (Ram and Klis 2006). The observed percent inhibitions of mycelial growth for the mixtures of prochloraz and Congo red at 0.05 to $0.4 \%(\mathrm{w} / \mathrm{v})$ were lower than the expected percent inhibitions of the mixture (Fig. 8A), indicating prochloraz may reduce chitin content in the cell wall of $S$. sclerotiorum.

SDS is an ionic surfactant and can dissolve membrane protein and lipid, thus disrupting the integrity of the cell membrane (Bulawa 1993). The observed percent inhibitions of mycelial growth for the mixture of prochloraz and SDS at 0.005 and $0.01 \%(w / v)$ were higher than the expected percent inhibitions (Fig. 8B), indicating prochloraz may disrupt the integrity of the cell membrane.

\section{Discussion}

The present study showed that sensitivity of S. sclerotiorum to prochloraz for isolates collected in 2014 did not decrease in comparison with that of 2008, hence no sensitivity shift occurred in field isolates. Prochloraz $\mathrm{EC}_{50}$ values, especially natural logarithms of the $\mathrm{EC}_{50}$ values, fitted a normal distribution. The distributions were similar in shape between 2008 and 2014. The distribution of $\mathrm{EC}_{50}$ values obtained in the present study could be used as a relative baseline sensitivity for future resistance monitoring programs. Within the context of fungicide resistance, baseline sensitivity is defined as a profile of sensitivity of previously unexposed individuals or populations of a target pathogen. By definition, baseline sensitivity should be constructed by sampling an adequate number of individuals of the target pathogen without an exposure history (Russell 2004). However, for various reasons, an adequate quantity of unexposed individuals or populations of the target pathogen may not be available or difficult to obtain. Under these circumstances, a relative baseline sensitivity, i.e., a sensitivity profile of the target pathogen with a previous exposure history but without a significant sensitivity shift, would be valid and valuable for future resistance monitoring programs. The reasons for the absence of a significant sensitivity shift in S. sclerotiorum from 2008 to 2014 might be the relatively low frequencies of prochloraz applications, as the dicarboximide fungicides dimethachlone and procymidone, and the benzimidazole fungicide carbendazim were the most widely-used fungicides for control of Sclerotinia stem rot on oilseed rape (Zhu 2003). Along with the development of resistance to dicarboximide fungicides in recent years (Zhou et al. 2014a), prochloraz will be used more often than ever for control of this pathogen. Previous studies showed that despite their site-specific mode of action, DMI resistance in various fungal pathogens evolves usually in a stepwise manner because DMI resistance is controlled by multiple genes, involving different mechanisms such as target-site modification, target gene (cyp51) overexpression, increased efflux, and multiple paralogues of the target gene (Ziogas and Malandrakis 2015). The Fungicide Resistance Action Committee (FRAC 2018) categorized DMI fungicides as being at medium risk for resistance development. Prochloraz resistance has been reported in various plant pathogens, including Penicillium digitatum (Wu et al. 2016), Pyrenophora teres f. sp. teres (Mair et al. 2016), and Fusarium verticillioides (Fan et al. 2014). With potentially more frequent applications of prochloraz, sensitivity of $S$. sclerotiorum to this fungicide should be closely monitored in future in case of resistance development, and the relative baseline sensitivity constructed in the present study can be used as a reference point.

Prochloraz $\mathrm{EC}_{50}$ values fitted a normal distribution but skewed to the right. Our previous studies showed that baseline sensitivity of S. sclerotiorum to the DMI fungicides flusilazole (Lu et al. 2015) and epoxiconazole ( $\mathrm{Li}$ et al. 2015), to the quinone outside inhibitor (QoI) fungicides pyraclostrobin (Liang et al. 2015a) and trifloxystrobin (Di et al. 2016), and to the dinitroaniline fungicide fluazinam (Liang et al. 2015b) all skews to the right. Studies with other pathogens also showed right-skewed distributions of baseline sensitivity, such as that of Pyrenophora tritici-repentis to pyraclostrobin (Patel et al. 2012), and $F$. virguliforme to the succinate dehydrogenase inhibitor (SDHI) fungicide fluopyram (Wang et al. 2017). It seems that most distributions of baseline sensitivities are right-skewed, whether fit a normal distribution or not. However, as demonstrated in the present and our previous studies, logarithms of $\mathrm{EC}_{50}$ values fit a normal distribution better and usually skew only slightly (Di et al. 2016; Liang et al. 2015a, b; Lu et al. 2015). Logarithmic transformation of $\mathrm{EC}_{50}$ data substantially improves distribution normality and homogeneity of variance and thus enhances the power and efficiency of statistical analysis (Liang et al. 2015c). Therefore, it might be better to use logarithms of $\mathrm{EC}_{50}$ values to establish baseline sensitivity of a target pathogen to a fungicide. The biological reasons for logarithmic transformation are that biological traits such as fungicide sensitivity are often mediated by multiple factors, as manifested by multiple resistance mechanisms. These multiple factors act more likely in a multiplicative rather than additive manner (Limpert et al. 2001).

The curative efficacy of prochloraz against $S$. sclerotiorum was much higher than that of the reference fungicide carbendazim. In effect, the curative efficacy of prochloraz was also higher than those of other DMI fungicides such as flusilazole (Lu et al. 2015) and epoxiconazole ( $\mathrm{Li}$ et al. 2015). Field efficacy trials showed that prochloraz
A

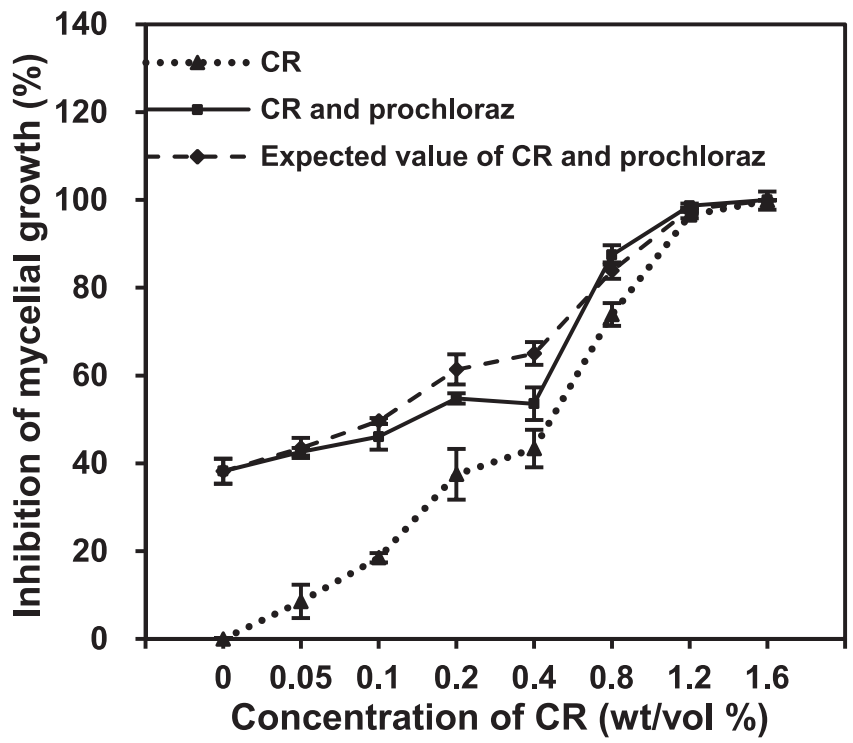

B

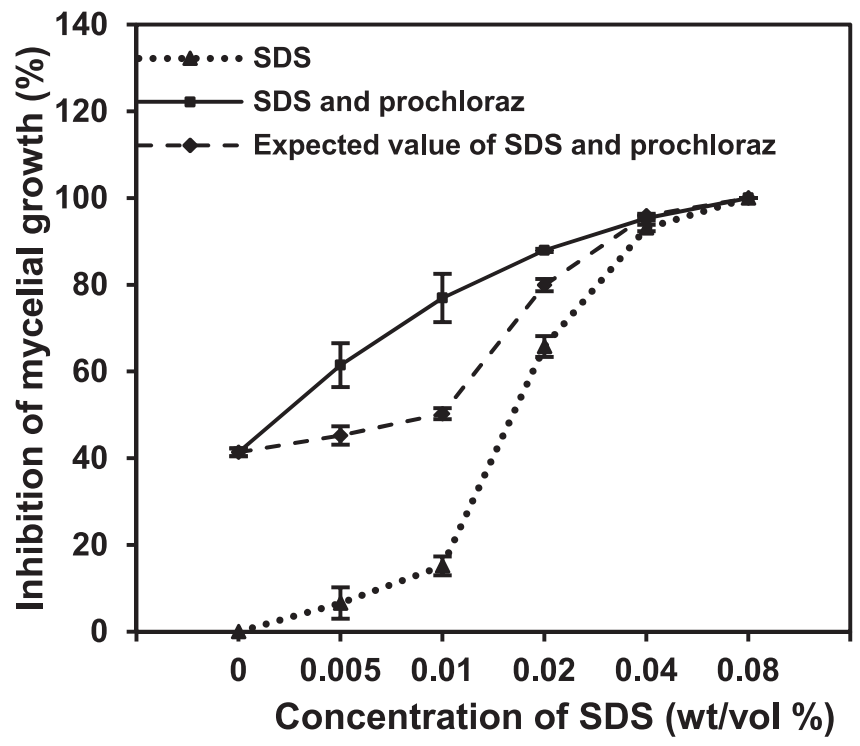

Fig. 8. Inhibitions of mycelial growth of Sclerotinia sclerotiorum on potato dextrose agar by A, Congo red (CR) and B, sodium dodecyl sulfate (SDS) in the presence or absence of prochloraz at $0.03 \mu \mathrm{g} / \mathrm{ml}$. Error bar denotes the standard error of the mean of three repeated experiments. 
has satisfactory preventive and curative activities against Sclerotinia stem rot of oilseed rape (Ren et al. 2010). In vitro experiment of the present study demonstrated that prochloraz at high concentrations increased the number of sclerotia per PDA plate while slightly decreased the weight of sclerotia. In contrast, flusilazole at high concentrations reduces both the number and weight of sclerotia per plate ( $\mathrm{Lu}$ et al. 2015).

The mode of action of DMI fungicides is to inhibit the demethylation during ergosterol formation, thus damaging cell membrane integrity of the target fungi (Ziogas and Malandrakis 2015). It is reasonable and logical to speculate that prochloraz might increase fungal cell membrane permeability by damaging membrane integrity. But experimental results showed prochloraz reduced rather than increased cell membrane permeability of $S$. sclerotiorum. Prochloraz at a higher concentration caused a greater decrease in cell membrane permeability. Our earlier studies also showed that flusilazole reduces cell membrane permeability of S. sclerotiorum (Lu et al. 2015). In these studies, cell membrane permeability is represented by the relative conductivity of distilled water containing mycelia, and the relative conductivity reflects the content of cytoplasmic leakage. However, cytoplasmic leakage of mycelia is influenced not only by cell membrane permeability but also by the thickness and hardness of the hyphal cell wall. TEM observations indicated that prochloraz caused $S$. sclerotiorum cell walls to become thicker, as reported for flusilazole (Lu et al. 2015). The thickening of the hyphal cell wall may be the primary reason for the reduced membrane permeability. Mannan is one of the major components of the fungal cell wall (Bowman and Free 2006). Prochloraz in PDA increased the weight percentage of mannan in S. sclerotiorum cells. This may partially account for the thickening of the hyphal cell wall. Another reason for the thickening of the cell wall may be the inhibited mycelial growth in the presence of prochloraz. Cytoplasmic leakage is likely low for the inhibited mycelia and thus leads to the reduced relative conductivity. The effects of prochloraz on the morphology of cell wall and organelles warrant further investigations in the future.

The present study showed that prochloraz increased sensitivity of $S$. sclerotiorum to SDS, indicating that prochloraz disrupted the integrity of the cell membrane. This phenomenon can be well explained by the established mode of action for DMI fungicides. However, prochloraz reduced sensitivity of $S$. sclerotiorum to Congo red. Congo red is believed to bind chitin of the cell wall, and reduced sensitivity to this reagent indicates a decrease in chitin content (Ram and Klis 2006). The significant effects of prochloraz on the contents of chitin and mannan in the cell wall indicate prochloraz has other toxic actions besides inhibiting demethylation during ergosterol formation.

In conclusion, relative baseline sensitivity of $S$. sclerotiorum to prochloraz was established in the study, and no shift in sensitivity to prochloraz occurred from 2008 to 2014 . In contradiction with its mode of action of inhibiting fungal ergosterol synthesis, prochloraz decreased rather than increased cell membrane permeability of mycelia. Further investigations showed that prochloraz caused cell walls to become thicker than the nontreated control, increased the content of mannan, but reduced the content of chitin in the cell wall. These studies indicate that prochloraz has significant effects on the morphology and component content of the fungal cell wall, and these results will deepen our understanding of the toxic actions of prochloraz on phytopathogenic fungi.

\section{Literature Cited}

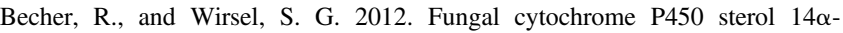
demethylase (CYP51) and azole resistance in plant and human pathogens. Appl. Microbiol. Biotechnol. 95:825-840.

Boland, G. J., and Hall, R. 1994. Index of plant hosts of Sclerotinia sclerotiorum. Can. J. Plant Pathol. 16:93-108.

Bolton, D. M., Thomma, B. P., and Nelson, B. D. 2006. Sclerotinia sclerotiorum (lib.) de Bary: Biology and molecular traits of a cosmopolitan pathogen. Mol. Plant Pathol. 7:1-16.

Bowman, S. M., and Free, S. J. 2006. The structure and synthesis of the fungal cell wall. BioEssays 28:799-808.
Bulawa, C. E. 1993. Genetics and molecular biology of chitin synthesis in fungi. Annu. Rev. Microbiol. 47:505-534.

Chen, Z. Y., Jiang, J. M., Xu, T. T., Shu, Y., Chen, G. Q., Wu, Z., and Zhang, Z. J. 2016. Determination of mannosan in beer yeast cytoderm. Feed Ind. 37:56-59.

Di, Y. L., Zhu, Z. Q., Lu, X. M., and Zhu, F. X. 2016. Baseline sensitivity and efficacy of trifloxystrobin against Sclerotinia sclerotiorum. Crop Prot. 87:31-36

Duan, Y. B., Ge, C. Y., Liu, S. M., Chen, C. J., and Zhou, M. G. 2013. Effect of phenylpyrrole fungicide fludioxonil on morphological and physiological characteristics of Sclerotinia sclerotiorum. Pestic. Biochem. Physiol. 106: 61-67.

Dyer, P. S., Hansen, J., Delaney, A., and Lucas, J. A. 2000. Genetic control of resistance to the sterol $14 \alpha$-demethylase inhibitor fungicide prochloraz in the cereal eyespot pathogen Tapesia yallundae. Appl. Environ. Microbiol. 66: $4599-4604$

Fan, J., Chen, F., Diao, Y., Cools, H. J., Kelly, S. L., and Liu, X. 2014. The Y123H substitution perturbs FvCYP51B function and confers prochloraz resistance in laboratory mutants of Fusarium verticillioides. Plant Pathol. 63:952-960.

FRAC. 2018. FRAC Code List 2018: Fungicide sorted by mode of action. http:// www.frac.info/docs/default-source/publications/frac-code-list/frac_code_list 2018-final.pdf?sfvrsn=6144b9a_2

Harris, F. A., and Chambers, H. W. 1973. Interaction of insecticidal mixtures in tobacco budworm. J. Econ. Entomol. 66:517-518.

Lees, N. D., Skaggs, B., Kirsch, D. R., and Bard, M. 1995. Cloning of the late genes in the ergosterol biosynthetic pathway of Saccharomyces cerevisiae - a review. Lipids 30:221-226.

Lepesheva, G. I., and Waterman, M. R. 2007. Sterol 14 alpha-demethylase cytochrome P450 (CYP51), a P450 in all biological kingdoms. Biochim. Biophys. Acta 1770:467-477.

Li, J. L., Liu, X. Y., Di, Y. L., Liang, H. J., and Zhu, F. X. 2015. Baseline sensitivity and control efficacy of DMI fungicide epoxiconazole against Sclerotinia sclerotiorum. Eur. J. Plant Pathol. 141:237-246.

Liang, H. J., Di, Y. L., Li, J. L., You, H., and Zhu, F. X. 2015a. Baseline sensitivity of pyraclostrobin and toxicity of SHAM to Sclerotinia sclerotiorum. Plant Dis. 99:267-273.

Liang, H. J., Di, Y. L., Li, J. L., and Zhu, F. X. 2015b. Baseline sensitivity and control efficacy of fluazinam against Sclerotinia sclerotiorum. Eur. J. Plant Pathol. 142:691-699.

Liang, H. J., Li, J. L., Di, Y. L., Zhang, A. S., and Zhu, F. X. 2015c. Logarithmic transformation is essential for statistical analysis of fungicide $\mathrm{EC}_{50}$ values. $\mathrm{J}$. Phytopathol. 163:456-464.

Limpert, E., Stahel, W. A., and Abbt, M. 2001. Log-normal distributions across the sciences - keys and clues. Bioscience 51:341-352.

Lu, X. M., Zhu, Z. Q., Di, Y. L., and Zhu, F. X. 2015. Baseline sensitivity and toxic action of flusilazole to Sclerotinia sclerotiorum. Crop Prot. 78:92-98.

Ma, H. X., Feng, X. J., Chen, Y., Chen, C. J., and Zhou, M. G. 2009. Occurrence and characterization of dimethachlon insensitivity in Sclerotinia sclerotiorum in Jiangsu Province of China. Plant Dis. 93:36-42.

Mair, W. J., Deng, W., Mullins, J. G. L., West, S., Wang, P., Besharat, N., Ellwood, S. R., Oliver, R. P., and Lopez-Ruiz, F. J. 2016. Demethylase inhibitor fungicide resistance in Pyrenophora teres $\mathrm{f}$. $\mathrm{sp}$. teres associated with target site modification and inducible overexpression of Cyp51. Front. Microbiol. 7:1279.

Pan, Y. L. 1998. The resistance of Sclerotinia sclerotiorum of rape to carbendazim and its management. Jiangsu J. Agric. Sci. 14:159-163.

Pan, Y. L., Zhu, G. M., Guo, J., Xiao, T., Chen, H. Z., and Yang, J. H. 2011 Sensitivity of Sclerotinia sclerotiorum to cyprodinil and correlation to fungicides. Chin. J. Oil Crop Sci. 33:499-502.

Patel, J. S., Gudmestad, N. C., Meinhardt, S., and Adhikari, T. B. 2012. Pyraclostrobin sensitivity of baseline and fungicide exposed isolates of Pyrenophora tritici-repentis. Crop Prot. 34:37-41.

Purdy, L. H. 1979. Sclerotinia sclerotiorum: History, diseases and symptomatology, host range, geographic distribution, and impact. Phytopathology 69:875-880.

Ram, A. F. J., and Klis, F. M. 2006. Identification of fungal cell wall mutants using susceptibility assays based on Calcofluor white and Congo red. Nat. Protoc. 1: 2253-2256.

Ren, L., Chen, K. R., Wang, C. Y., Luo, L. X., Jia, J. G., Wang, J., and Fang, X. P. 2010. Potential of prochloraz-manganese chloride in controlling Sclerotinia stem rot of oilseed rape. Sci. Agric. Sin. 43:4183-4191.

Russell, P. E. 2004. Sensitivity baselines in fungicide resistance research and management. FRAC Monograph No. 3. Brussels, Belgium. http://www.frac info/docs/default-source/publications/monographs/monograph-3.pdf?sfvrsn= 629d419a_8

Shi, Z. Q.,Zhou, M. G., and Ye, Z. Y. 2000. Resistance of Sclerotinia sclerotiorum to carbendazim and dimethachlon. Chin. J. Oil Crop Sci. 22:54-57.

Sombardier, A., Dufour, M. C., Blancard, D., and Costet, M. F. C. 2010 Sensitivity of Podosphaera aphanis isolates to DMI fungicides: Distribution and reduced cross-sensitivity. Pest Manag. Sci. 66:35-43.

Sun, Z. X., Deng, L., Zhang, C. Q., and Zhou, Y. 2015. Toxicity of several fungicides and chemical mixture against Sclerotinia sclerotiorum. Hubei Agric. Sci. 54:1606-1608 
Vinggaard, A. M., Hass, U., Dalgaard, M., Andersen, H. R., Bonefeld-Jørgensen, E., Christiansen, S., Laier, P., and Poulsen, M. E. 2006. Prochloraz: an imidazole fungicide with multiple mechanisms of action. Int. J. Androl. 29:186-192.

Wang, J., Bradley, C., Stenzel, O., Pedersen, D. K., Reuter-Carlson, U., and Chilvers, M. I. 2017. Baseline sensitivity of Fusarium virguliforme to fluopyram fungicide. Plant Dis. 101:567-582.

Wu, Z., Wang, S., Yuan, Y., Zhang, T., Liu, J., and Liu, D. 2016. A novel major facilitator superfamily transporter in Penicillium digitatum, (pdmfs2) is required for prochloraz resistance, conidiation and full virulence. Biotechnol. Lett. 38:1349-1357.

Yu, Y., Jiang, D. H., Xie, J. T., Cheng, J. S., Li, G. Q., Yi, X. H., and Fu, Y. P. 2012. Ss-S12, a novel cell wall protein with PAN modules, is essential for sclerotial development and cellular integrity of Sclerotinia sclerotiorum. PLoS One 7:e34962.

Yun, Y. Z., Yin, D. F., Dawood, D. H., Liu, X., Chen, Y., and Ma, Z. H. 2014. Functional characterization of FgERG3 and FgERG5 associated with ergosterol biosynthesis, vegetative differentiation and virulence of Fusarium graminearum. Fungal Genet. Biol. 68:60-70.

Zhang, H. F., Liu, K. Y., Zhang, X., Song, W. W., Zhao, Q., Dong, Y. H., Guo, M., Zheng, X. B., and Zhang, Z. G. 2010. A two-component histidine kinase,
MoSLN1, is required for cell wall integrity and pathogenicity of the rice blast fungus, Magnaporthe oryzae. Curr. Genet. 56:517-528.

Zhang, X. L., Sun, X. M., Zhang, G. F., Yi, H. J., and Qiang, Y. 2003. Preliminary report on the monitoring of the resistance of Sclerotinia sclerotiorum to carbendazim and its integrated management. Chin. J. Pestic. Sci. Adm. 24: $18-22$

Zhou, F., Zhang, X. L., Li, J. L., and Zhu, F. X. 2014a. Dimethachlon resistance in Sclerotinia sclerotiorum in China. Plant Dis. 98:1221-1226.

Zhou, F., Zhu, F. X., Zhang, X. L., and Zhang, A. S. 2014b. First report of dimethachlon resistance in field isolates of Sclerotinia sclerotiorum on oilseed rape in Shaanxi Province of northwestern China. Plant Dis. 98:568.

Zhu, W. J., Wei, W., Fu, Y. P., Cheng, J. S., Xie, J. T., Li, G. Q., Yi, X. H., Kang, Z. S., Dickman, M. B., and Jiang, D. H. 2013. A Secretory protein of necrotrophic fungus Sclerotinia sclerotiorum that suppresses host resistance. PLoS One 8:e53901.

Zhu, Y. L. 2003. Reasons for the outbreaks of Sclerotinia stem rot of oilseed rape and integrated management tactics. Anhui Agric. Sci. Bull. 9:63-66.

Ziogas, B. N., and Malandrakis, A. A. 2015. Sterol biosynthesis inhibitors: C14 demethylation (DMIs). Pages 199-216 in: Fungicide Resistance in Plan Pathogens. H. Ishii and D. Hollomon, eds. Springer, Tokyo. 